Journal of English Language Teaching and Applied Linguistics

ISSN: 2707-756X

DOI: $10.32996 /$ jeltal

Journal Homepage: www.al-kindipublisher.com/index.php/jeltal

JELTAL

\title{
Thinking Outside the Box (Below and Above it, Too): Perspectives toward critical thinking in TESOL in Vietnam
}

\author{
Luan Tuyen Chau 18 (D) and Aliel Cunningham 2 8 \\ ${ }^{1}$ MA TESOL thesis student at LCC International University, Lithuania \\ ${ }^{2}$ TESOL professor at LCC International University, Lithuania \\ $\triangle$ Corresponding Author: Luan Tuyen Chau, E-mail: cluan18@students.Icc.It
}

\begin{tabular}{|c|c|}
\hline ARTICLE INFORMATION & ABSTRACT \\
\hline $\begin{array}{l}\text { Received: March 02, } 2021 \\
\text { Accepted: April 11, } 2021 \\
\text { Volume: } 3 \\
\text { Issue: } 4 \\
\text { DOI: } 10.32996 / \text { jeltal.2021.3.4.2 }\end{array}$ & $\begin{array}{l}\text { The incorporation of critical thinking into ESL teaching and curricula has been } \\
\text { debated in second language pedagogy for decades. Prior publications have shown } \\
\text { that the teaching and learning of critical thinking is a complicated issue due to both } \\
\text { cognitive and sociocultural factors. In this questionnaire study, we had an opportunity } \\
\text { to survey } 12 \text { instructors and } 37 \text { students at a public university in Vietnam about their } \\
\text { viewpoints on critical thinking instruction in language teaching. In contrast with the }\end{array}$ \\
\hline $\begin{array}{l}\text { Critical thinking, language } \\
\text { teaching, second language } \\
\text { pedagogy, TESOL, Asia }\end{array}$ & $\begin{array}{l}\text { common notion that many collectivistic cultures in Asia do not nurture critical analysis } \\
\text { and sceptical questioning, both instructors and students in Vietnam demonstrated a } \\
\text { hospitable view towards the practice of teaching critical thinking in English } \\
\text { classrooms. However, instructors experience immense difficulties incorporating this } \\
\text { concept into their curricula due to a lack of resources, training and time pressure. The } \\
\text { current study indicates a need for critical thinking in ESL classrooms in Vietnam and } \\
\text { provides concrete guidelines for introducing critical thinking into second language } \\
\text { classes. }\end{array}$ \\
\hline
\end{tabular}

\section{Introduction}

"Education must enable one to sift and weigh evidence, to discern the true from the false, the real from the unreal, and the facts from the fiction. The function of education, therefore, is to teach one to think intensively and to think critically." - Martin Luther King, Jr.

The introduction of teaching and evaluating critical thinking skills along with language skills in TESOL classrooms has been a much-debated concept in second language research. In the late 1990s, many authors questioned incorporating critical thinking into second language teaching and learning because of potential complicating issues (Atkinson \& Ramanathan, 1995; Ramanathan \& Kaplan, 1996; Atkinson, 1997). These authors argued that language instruction should be only language-specific, and the exclusion of critical thinking in teaching would minimize the number of cultural and pedagogical complications. Over the past 2 decades, however, critical thinking has accelerated from an estranged subject to what many see as an essentialized component of global English classrooms. The trend is now for both teachers and researchers in the TESOL field to see TESOL and critical thinking topics as complementary to one another and welcome more discussion on how to incorporate critical thinking into the second language classroom. Such change is happening primarily because of three reasons. Firstly, second language education has risen from language-specific approaches to more holistic perspectives on more general educational and sociocultural values, including critical thinking (Kumaravadivelu, 2006). Secondly, as English increasingly becomes the main language of science and technology, today's learning and teaching must go beyond basic communication purposes in social contexts (Hinkel, 2006). English education is now intended to facilitate academic success for international students. Finally, we are constantly surrounded by fake news, click baits, and hoaxes on news and the media (Aldwairi \& Alwahedi, 2018). Critical thinking now serves as a survival tool for everyone in the age of information, rather than being viewed as an elite "academic talent" utilized only by those pursuing advanced degrees.

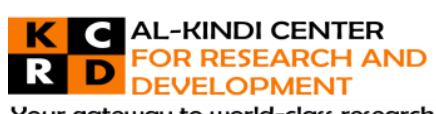

Your gateway to world-class research

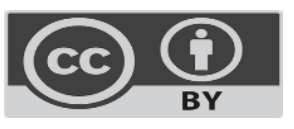

Published by Al-Kindi Center for Research and Development, United Kingdom. Copyright (c) the author(s). This open access article is distributed under a Creative Commons Attribution (CC-BY) 4.0 license 
Despite its importance, the incorporation of critical thinking into English language teaching curricula has never been an easy task. According to Atkinson (1997), the inclusion of critical thinking in L2 classrooms is fraught with many cultural problems. He maintained that critical thinking is a "non-overt social practice" built upon underlying cultural norms and assumptions that cannot be explicitly taught. Consequently, the teaching of critical thinking to non-native speakers, especially to those whose culture embraces a high level of social hierarchy and obedience to prevalent norms, is considered "risky" and "ineffective". One controversial issue raised by Ramanathan and Kaplan (1996) and Atkinson (1997) was that Asian learners of English were perceived to be "more passive", "more shy", and "less capable critical thinkers" who are less willing to take part in debates on controversial topics than their Western counterparts. However, sociolinguistic studies in second language research have proved that these assumptions do not reflect reality (Littlewood, 2000; Stapleton, 2002; Kumaravadivelu, 2003). Asian learners are willing to think critically and think beyond the materials if they are given the right opportunities (Littlewood, 2000; Stapleton, 2002; Kumaravadivelu, 2003). They do not perceive their teachers as an embodiment of knowledge or a figure of authority. Instead, they want to question what they have been taught and interact proactively with the materials and the classroom content.

Still, the culture of education and assessment systems in many South-East Asian countries do not accommodate many learners' aspirations to be more active in their learning: teacher-centred classrooms are still the dominant types of classroom in these regions; textbooks are still designed in a way that gives students no motivation to think beyond the content; homework remains a redundant workload that teachers do not have enough time to finish in class; tests and exams are simply the arenas where students regurgitate what they have learnt in class and race for meaningless grades. As a learner who grew up in this system, I have witnessed a number of disadvantages of this teaching and learning philosophy. Students mostly rely heavily on rotelearning mechanisms within these boundaries where they are trained to remember specific content rather than deeply understand it. Consequently, they are deprived of real opportunities to question and assess what they have been told and think beyond the textbook framework's perspectives.

The situation of education in Vietnam is a good reflection of all the problems mentioned above. English is widely taught in many secondary schools, high schools, colleges, and universities. However, the English language teaching and learning in Vietnam have long been confined to the teaching and learning of pure grammar, especially in high school education. Over the past 20 years since the "economic reform", there has not been much progress in English teaching and learning in Vietnam. A typical English class in Vietnamese high schools starts with a teacher presenting a grammatical structure on the blackboard and ends with students solving grammar exercises relating to the structure they have learnt. Little attention is given to the spoken language aspect, and communicative practice is nearly non-existent. As a result, after years of learning, few Vietnamese students can communicate successfully in English. They rarely have the chances to speak up and genuinely use the language in a class context because the accepted teaching style assumes the teacher's presence in the central, dominating figure in all classroom interactions. Critical thinking, unsurprisingly, has been considered a luxury item the teachers cannot afford - both in terms of time and traditional expectations of their role in the classroom. This is true of all subjects in Vietnam, including English classes.

Previous TESOL articles that have discussed the presence of critical thinking in language teaching have centered around two main issues: (a) debating the merits of including explicit instruction in critical thinking (Atkinson \& Ramanathan, 1995; Ramanathan \& Kaplan, 1996) and (b) discussing the cultural problems of incorporating critical thinking into TESOL (Atkinson, 1997). Few studies have actually suggested concrete and practical pedagogical guidelines on the inclusion of critical thinking in language teaching (see Oda, 2008 for a review). More importantly, incorporating critical thinking into foreign language assessment has been unexplored. Wanting to understand this issue from both the instructor and student point of view, we initiated a qualitative study into the different viewpoints on critical thinking in TESOL from 60 students and 12 lecturers from Ton Duc Thang University in Vietnam to explore this topic in depth. We established two major goals for this research project: (1) Firstly, to examine critical thinking status in English classrooms in Vietnam. We are particularly interested in how Vietnamese teachers and learners define critical thinking and whether they are hospitable to its presence in language learning and teaching. (2) Secondly, to resolve some of the potential problems in training students to think critically when teachers have limited resources or insufficient experience. As a result of this study, we hope to ascertain concrete guidelines for promoting and integrating critical thinking in language curricula and formal assessment in Vietnam and other similar English language teaching contexts.

The study aimed to address the following research questions based on an analysis of qualitative data gathered from responses to open-ended questionnaires by lecturers and students at a public research university in Vietnam:

a. How do Vietnamese lecturers and students define critical thinking according to their educational and cultural experiences?

b. Are Vietnamese lecturers and students hospitable to the presence of critical thinking in ESL classrooms?

c. How do Vietnamese lecturers incorporate the teaching and learning of critical thinking into ESL curricula and what are some of the potential difficulties when implementing this practice? 


\section{Design of Study \\ 2.1. Participants and Context}

Our participants were students and teaching staff at the Faculty of Foreign Languages from Ton Duc Thang university - a public research university in Vietnam. The number of participants included was 12 full-time English lecturers and 37 English students. All the chosen lecturers have at least 5 years of teaching experience. Their teaching responsibilities include a wide range of English language subjects, such as Academic English skills, English language and linguistics, American and British culture, English literature, and integrated skills in English. Half of the lecturers reported that they read daily news in English on a regular basis.

The students were majoring in Bachelor of Arts in the English Language, with a TESOL specialisation. The program is intended to train students to become professional teachers in public and private language schools. The curriculum's core subjects include methods of second language pedagogy, second language acquisition, English literature, and linguistics of English. Most student participants have studied English for at least 9 years or more. This particular group of students was interested because they were studying to become language teachers soon. Several of them had taught English classes as part-time jobs to draw on their experience as both a student and a teacher.

Ton Duc Thang University is one of the leading universities in Vietnam and South-East Asia. The university has a mission to cultivate academic integrity, independent thinking, creativity, logical planning, and many other educational values into its curriculum; critical thinking is among these valuable skills that help the student become both ethical and professional working individual in the $21^{\text {st }}$ century.

\subsection{Developing the Questionnaire}

Two open-ended questionnaires were given to our participants. One questionnaire was given to the lecturers and the other to the students. Both questionnaires consisted of seven questions that aimed to elicit lecturers' and students' perspectives toward the inclusion of critical thinking skills into English language learning and teaching. The questionnaires were written in Vietnamese due to time constraints and varying proficiency levels in written English among the participants. Participants' responses were later translated into English for thematic content analysis. The questionnaires include three sections (Section A, B, and $C$ ). Section $A$ is a brief introduction of the study, including our research purposes, participants' responsibilities, and a lookahead plan for the rest of the questionnaire. In Section B, participants were asked to fill in basic demographic information, such as gender, age, years of learning English (for students), years of teaching English (for lecturers/ if applicable for students), and whether they read news in English frequently. Section C - The study's main section consists of 7 open-ended questions relating to critical thinking skills. Each question is followed by some spaces where participants can write their responses in short paragraphs.

The seven questions included in the questionnaires were:

1) Do you think that it is difficult to define critical thinking? How do you define the concept?

2) Do you think critical thinking should be a part of English language learning and teaching?

3) What do you think are some of the difficulties that Vietnamese lecturers and students may encounter when incorporating critical thinking skills into ESL curricula?

4) Do you suggest any strategies or implementation of teaching practices that help cultivate critical thinking into ESL learning and teaching?

5) How does the teaching and learning of critical thinking benefit students and lecturers?

6) In what ways can the inclusion of critical thinking be harmful/ irrelevant for ESL curricula?

7) How often do you discuss or encourage critical thinking skills in your classrooms? If yes, what are some of the practices you often use when teaching critical thinking for students? (For the students' questionnaire, the question is: How often do your lecturers discuss or encourage critical thinking skills in their classrooms? If yes, what are some of the practices they often use when teaching critical thinking skills for you?)

\subsection{Data Collection and Analysis}

The researcher discussed the potential project with one faculty member from the Faculty of Foreign Languages at Ton Duc Thang university over email one month before conducting the study. Because the researcher could not be physically present when the data collection occurred, this partnering faculty member coordinated the questionnaires' distribution to the students and other faculty members. The lecturers and students took the questionnaires home and completed them at their convenience to allow the participants ample time to think and reflect on their learning and teaching experiences and contexts. After two weeks' time, the faculty member helped facilitate the collection of all the questionnaires. That faculty member was also one of the 12 lecturers who participated in the study.

Students and lecturers' questionnaires were scanned to the researcher for data analysis. The participants were not required to provide any personal or sensitive identifying information when completing the questionnaire responses. All data collection was handled with confidentiality and anonymity. The responses were given in the aggregate form. No given information could be 
used to track or reveal the identity of the people who participated in responding to the questionnaire. Participants' responses were first translated into English by the researcher. The data was inductively coded and organized by keyword codes which were then translated into broader themes and categories. Thematic content analysis was conducted in order to answer the three research questions.

\section{Results and Discussion}

In this section, we report major findings that emerged from a thematic analysis resulting from coding lecturers' and students' responses. The key themes that address the study's three research questions are as follows:

\section{Research Question 1: How do Vietnamese lecturers and students define critical thinking according to their educational and cultural experiences?}

a. Lecturers' views: The lecturers defined critical thinking in their context according to references from the Bloom's taxonomy. The idea that the process of learning and acquiring information can be broken down into different levels on a top-down pyramid. One prominent theme that emerged from the lecturers' responses was the notion that critical thinking is a cognitive ability that involves a conglomeration of logical evaluation, selective analysis, and reflection on issues and matters. Another theme related to the goal of critical thinking - that its primary goal should be seen as reaching informed personal conclusions and being able to make appropriate judgements. From a pedagogical perspective, some lecturers emphasized the role of background knowledge and personal experiences in developing critical thinking skills. They emphasized that critical thinking skills do not exist in empty vessels or appear of nowhere but act as a bridge between the old (i.e. something the thinker already knows) and the new (i.e. new perspectives, the alternatives). Other lecturers referred to critical thinking as a higher-order cognitive ability to challenge and argue against logical fallacies. In this respect, critical thinking was regarded as a tool for generating questions and inquiries. Critical thinkers have a habit of digging into objects of inquiries, challenging the norms, and asking deeper questions.

b. Students' views: There were relatively mixed responses on how critical thinking should be defined when we asked them to pin down this concept. Overall, nearly half of the students stressed the importance of information literacy when thinking critically. According to these responses, to think critically is to re-assess information accuracy by asking critical questions and validating arguments via references to a wide range of information sources. For many students, critical thinking is considered a necessary tool for those pursuing truth and correctness. When an individual is a good critical thinker, that individual can distinguish opinions from facts, knowledge from information, truth from rumor, and contributive criticism from prejudices. Critical thinkers should also justify the validity and reliability of information sources before jumping to conclusions.

An approximately equal number of students defined critical thinking as considering multiple perspectives when assessing an issue or a question of interest. They said an individual is a critical thinker when he/she approaches an issue from multiple angles, and to think critically is to consider a matter from several angles. These students characterized higher order thinking as "objective, informative, and divergent". Divergent thinking helps an individual realize different ways of thinking and approach an issue. As a result, critical thinkers learn to respect opinions different from theirs, which is the most important objective of learning to think critically in an ESL classroom where we have different personalities, learning styles, perspectives, and mindsets. Critical thinking is a valuable way for teachers and students to cultivate respect and hospitality in the curriculum.

Besides, many other students identified problem-solving skills as critical learning elements to think critically. Critical thinking helps learners create multiple solutions to the same problem for them. With a wide range of possibilities and alternatives, learners can reflect on the most effective solution to tackling an issue. In this respect, these students characterized critical thinking as "enlightening, realistic, and creative".

Other responses revealed a relative mixture of opinions on the definition of critical thinking. Some students emphasized the importance of relating to personal experiences during critical thinking. According to these students, a learner is a critical thinker when he/she can synthesize information and absorb knowledge after reflecting carefully on his/her personal circumstances. A concept or a solution may be applicable in many contexts but useless in others. To that end, thinking critically is equivalent to distinguishing between those facts or ideas that are usable or relevant within a given context versus those that are not. One student identified skeptical reasoning as the sole definition of critical thinking. Other students defined critical thinking as refuting opposing arguments and putting forward personal opinions. These students argued that a competent critical thinker should know how to identify and attack weaknesses in opposing arguments. 


\section{Research Question 2: Are Vietnamese lecturers and students hospitable to the presence of critical thinking in ESL classrooms?}

This research question focuses on two particular themes: (i) whether lecturers and students welcome the incorporation of critical thinking into their ESL classrooms and (ii) whether lecturers and students recognize the benefits of this practice and what is their rationale for their position?

a. Lecturers' views: All the lecturers agreed that critical thinking should become a part of English language teaching and learning in Vietnam. One lecturer even said that critical thinking teaching should be mandatory. Another lecturer believed this teaching practice is an inevitable change that speaks to teaching English as an international language in the $21^{\text {st }}$ century. It is not uncommon to find embedded in many current textbooks a section dedicated to critical thinking skill practice. Often, critical thinking exercises are included at each unit's conclusion, especially in ESL / EFL curriculum focused on academic reading and writing.

Overall, the lecturers supported including logical analysis and higher-order thinking skills into their teaching plans because of several benefits. First, critical thinking spurs on developing independent thinking and active learning, which serves as a foundation for building a student-centered classroom. Also, many lecturers have considered critical thinking as a tool for teaching the pragmatics of language contending that language is not a set of habits and learning the language is not merely a process of memorizing and practising a rigid set of rules. Language learning was described more as a logical analysis process and practical application of theories and knowledge into appropriate contexts. Furthermore, some lecturers observed a tremendous change in teaching English in the modern age, when ESL textbooks' content touches upon many complex issues that belong to different disciplines. From this vantage point, critical thinking was understood as a thinking tool that helps students work effectively with cross-disciplinary topics. Some lectures voiced the hope that teaching critical thinking in TESOL classrooms could promote more interactive and dynamic interaction between student and teacher.

b. Students' views: Nearly all the students supported the incorporation of critical thinking into English language teaching and learning for a variety of reasons. The majority of participants expressed the notion that learning to think critically when learning English helps them acquire more integrated sets of skills, which brought together both their language learning and metacognitive skills. A wide range of skills that critical thinking mentioned by the students bolster includes communicative competence, confidence building, the improvement of the four main language skill areas, creativity, problem-solving skills, reinforcement and consolidation of language knowledge, reasoning skills, discourse skills, the ability to verbalize thoughts and personal perspective, and ensuring objectivity in building arguments after considering multiple perspectives of an issue. Most responses emphasized that creative thinking and problem-solving skills are among two of the most critical gains when learning to think more critically. In addition, many students also said that critical thinking is one of the most effective ways to help develop learners' autonomy. Learners are provided with the opportunities to step outside of the traditional classrooms where teachers control everything and tell them what to do step by step. With critical thinking, learners have more tools to better reflect on their own learning progress to research and decide which learning strategies work best for them and develop independent thinking skills.

Interestingly, several students mentioned that the greatest advantage of incorporating critical thinking into ESL classrooms is that it improves the communication and rapport between students and teachers. These perspectives arise from the philosophy that education is not an environment where students learn from teachers, but it is a place where both teachers and students learn and grow together. Therefore, the teaching of critical thinking helps teachers and students understand one another's perspectives better, and students are given the framework and encouragement to express their voice. Thus, teachers can keep track of their students' knowledge and appreciate different viewpoints in their classrooms. Also, instructors can make themselves seem less distant from students when they allow students to verbalize their thoughts and provide a forum for the expression of personal opinions to be heard and discussed. Instructors can then improve their teaching quality and adapt teaching materials to better suit students' needs and interests.

Despite major responses in support of the teaching of critical thinking, one student was concerned that critical thinking is a difficult skill that requires a great amount of time and effort on the part of both student and teacher. This student voiced the concern that only students with high language proficiency would able to adapt to a new teaching and learning style, and weaker students may suffer from a lot of psychological stress and tension to familiarize themselves with this change. Consequently, the incorporation of critical thinking in ESL may become counter-productive and discouraging for many students who are not very adaptable due to their personalities or level of language proficiency. 


\section{Research Question 3: How do Vietnamese lecturers incorporate the teaching and learning of critical thinking into ESL curricula and what are some of the potential difficulties when implementing this practice?}

For this research question, we examine two issues: (i) in what ways our lecturers normally teach critical thinking skills to their learners and (ii) what some of the potential difficulties they face are when implementing this teaching practice in their classrooms.

a. Lecturers' views: When asked how often they discuss critical thinking in classes, our lecturers provided very mixed responses. Only 4 out of 10 lecturers were confident that they frequently discuss critical thinking skills in their classrooms. Other lecturers did not give an explicit answer on this, and 3 lecturers said they rarely or hardly ever talked about this concept with their students. The most common approach that was suggested and described as being practiced in the classroom was to ask openended and critical questions. Other techniques that were mentioned included organizing seminars, debates, and discussion activities for students. One lecturer suggested the importance of playing devil's advocate to ignite discussion and debates in classrooms.

According to their questionnaire responses, two major obstacles related to teaching critical thinking skills to Vietnamese students were highlighted. First, the ability to think critically is influenced by a number of cultural factors. In Vietnam, the teacher-centered model remains the dominant mode of delivering lessons. Vietnamese students are familiar with absorbing knowledge passively from their teachers. Teachers are considered a transmitter of knowledge whose words are not to be questioned, rather than as a resource, a facilitator, or a mentor. Incorporating critical thinking skills into ESL curricula requires both students and teachers to assume roles and habits that run counter to this teacher-centered paradigm. Second, the time constraint is another major problem that deters critical analysis teaching and learning. Program administrators tend to provide very little time and space for teachers to construct a student-centered classroom. Simultaneously, language assessment in Vietnam is primarily intended to measure the amount of textbook content students can remember, which provides little space or motivation for students and teachers to go beyond what is discussed and addressed in the coursebooks.

b. Students' views: Many responses revealed that instructors rarely discuss critical thinking in ESL classrooms. Some of the most common strategies observed in classes include asking questions, encouraging students to ask questions, organizing Q\&A sessions after group presentations, note-taking strategies while listening to lectures and watching videos, group debate and discussion, games and activities, role plays, and problem-solving exercises. However, these activities are not often included as a regular part of learning and teaching. When asked what activities can be included to promote critical thinking in their learning environment, most participants gave very vague responses and suggestions. Some of the most common suggestions include organizing small group and large group discussion, building students' confidence via readings, improving students' background knowledge, encouraging students to speak up their opinions regardless of the accuracy of their responses, and practicing independent thinking in class. Several students mentioned the importance of taking small steps in training students to think critically. Students should be exposed to basic levels of critical thinking before they are ready to move on with more advanced critical thinking exercises.

Regarding the reservations and pitfalls of discussing critical thinking in ESL teaching and learning, all the students say there are no pitfalls or potential dangers of training students to think critically. However, some students mentioned that it might take a great deal of time and effort to familiarize Vietnamese students with this concept because critical thinking is not usually discussed in many courses and subjects in Vietnam. As a result, they suggested that instructors need to do it with gradual steps and a carefully considered approach.

\section{General Implications and Guidelines for Teaching Critical Thinking Skills}

The results reported in this study suggested that both Vietnamese instructors and students appreciated and welcomed critical thinking in ESL curriculum and teaching programs. Both groups showed a strong desire for learning and talking about higherorder thinking skills and critical reasoning when learning English. However, there is a mismatch between students' expectations and instructors' teaching practices. More significantly, it seems that English instructors do not know how to incorporate critical thinking systematically into their teaching practices although they recognize its importance in learning and teaching a second language. This section provides some concrete guidelines that may serve as a useful framework for teachers as they attempt to train students to think critically in their classrooms. The guidelines here are only references and not rules to be rigidly applied or adhered to. As not all the guidelines are applicable or practical in all teaching scenarios, teachers should adapt these strategies to suit learners' interests and needs. 


\section{Guideline 1: Teachers should train students to see multiple perspectives over an issue}

According to Purgason (2016), critical thinkers are curious and inquisitive. They should understand that every story has more than one side. Critical thinkers look for multiple sources to verify the accuracy of the information they are exposed to and are skeptical of stories or articles that simply show pure black and white or good and evil. Purgason (2016) suggested that teachers teach critical thinking whenever they supplement reading with another text about the same topic but written from a different perspective. For example, a teacher should look for two different veganism readings (one article could be about the benefits of becoming a vegan and one article about some drawbacks of becoming a vegan). Veganism benefits could include humanitarian values, religious practices, environmental factors, or health-related issues. Veganism is often depicted as humane, healthy, and environmentally friendly. However, some drawbacks of being a vegan include difficulties with socializing, lack of necessary nutrients, fatigue, and high expenses. By showing different viewpoints, teachers can train students to think critically as recognising many sides of an issue is regarded as one of the core values of critical thinking.

\section{Guideline 2: Teachers should not simply ask questions directed at the students but let students ask critical questions directed at themselves}

Asking questions is one of the most common ways teachers use to elicit responses and language from students. However, it is considered as one of the main ways to help teachers keep track of students' knowledge and check their understanding. In many circumstances, the teacher asks their questions and already form an expected answer in mind. When asking question directed at students, teachers only expect one student among many to say the answer that is already on their mind. Whenever we ask questions, however, we have an opportunity to teach critical thinking if we welcome a wide range of possible responses and are willing to take time to engage in discussion about the rationale given for each answer or discussion about each answer's merit or relevance.

In order to encourage critical thinking, teachers could try letting students form their own questions relating to lessons or materials discussed in class. After that, they can discuss those questions and their classmates to look for appropriate and logical answers. Critical questions should be related to information literacy.

\section{Guideline 3: Teachers should train students to make better and more ethical decisions}

One of the most important goals in education is to teach students to make better decisions. Decision-making is a very complicated psychological process, and during the path of learning something new, students are forced to make decisions according to different scenarios and contexts. For example, students have to choose to agree or disagree and take a stance whenever they have to write an argumentative essay to present their arguments. Their performance is assessed according to how well they can organize their ideas within passages and provide concrete examples and evidence to support their arguments. This is something that students do regularly, but many students are not provided with a solid foundation or a concrete framework that can help them draft their ideas and organize their thoughts more systematically.

One framework that teachers can use to train students to make more informed decisions is the model of Six Thinking Hats, first suggested by Edward De Bono. The model was originally developed for CEOs to make more economical decisions regarding cutting down expenses or making any new changes in their business environments. De Bono's Six Thinking Hats was then applied to education. Several empirical studies have confirmed the benefits of using this thinking model to improve learners' thinking, and these benefits are observed across a wide range of disciplines and areas, including general education (Chone \& Heng, 2010; Karadag et al., 2009), teacher education (Chien, 2020), and language training (Hani et al., 2017; Swamy et al., 2019).

De Bono's Six Hats Thinking model divides critical analysis of any issue into six categories of thinking. The mentioned six hats in the model include (1) White Hat - gathering information, (2) Green Hat - innovation and creation of new ideas, (3) Yellow Hat considerations of all the advantages or benefits of an issue or an idea, (4) Black Hat - considerations of all the disadvantages or pitfalls of an issue or an idea, (5) Red Hat - feelings and intuitions toward an issue, and (6) Blue Hat - synthesis and summary of information from other hats to reach conclusions. Teachers can use this framework to help students see multiple perspectives of an issue and make more informed decisions when they have to take a stance to present their arguments during brainstorming ideas for their essay. For example, when students are asked to write an opinion essay on whether it is considered justice to take revenge on people who hurt us, teachers can divide students into groups and ask them to list all the ideas associated with each hat in groups. Ideas generated from the Red Hat may encourage people to see revenge as a rightful and equal act because it is a natural reaction to pain, anger, agony. Thinking with the Yellow Hat, all the advantages of taking revenge on our enemies should be mentioned: such as "Revenge makes us feel better." With the Black Hat, students should list all the pitfalls of taking revenge: such as "Retribution is an endless cycle and does not change anything." With the White Hat, students generate critical questions to assess ideas generated from the Yellow Hat and Black Hat: such as "Does revenge make us feel any better? Does this 'better' and 'satisfying' feeling last long?" Students use the Green Hat to generate any extraordinary ideas that are different than other 
ideas that have already been generated. For instance, "Revenge can manifest in many more humane ways: forgiving others to regain personal happiness and walking away from those who hurt us is the best revenge." Finally, with the Blue Hat, students synthesize multiple ideas from the five hats and choose whether to write an essay that supports or discourages retribution.

\section{Guideline 4: Teachers should enlist the use of technology when integrating critical thinking into teaching and learning}

Several computer apps and digital platforms can serve as a great resource for teachers to cultivate critical thinking into their curriculum. Ted Talks are one of the most reliable channels where students can be exposed to a great deal of academic and argumentative topics of the $21^{\text {st }}$ century. They can practice their vocabulary, listening skills, and reasoning abilities via listening to Ted's different speeches. Due to some Teds' varied time lengths, the use of Ted would be more ideal when it is embedded as online components of an e-learning system, instead of a class activity. Teachers can create forums to contribute different ideas and comments after listening to some Teds. Some questions that act as prompts for students to think around the topic are highly advisable. Students can also comment on their classmates' thoughts in order to see that not everyone thinks the same way.

\section{Guideline 5: Teachers should introduce critical thinking in the pre-stage and consolidate it in the post-stage of a lesson}

Teachers may wonder when they should discuss critical thinking during the stage of a listening, reading, writing, and speaking lesson. There seems to be no fixed answer to this. Nevertheless, teachers may explicitly introduce areas and concepts that they want to draw students' attention to during critical thinking and consolidate the process in the post-stage. It is worth noting that students should think critically throughout the lesson, and think critically is an ongoing process. When teachers can help students be less dogmatic and open to new ideas, they have succeeded in training students to think critically. Students may form some biases and prejudices toward certain topics and subjects at the beginning of the lesson. At the end of the lesson, the goal is for students to see the issue differently from the way they saw it at the beginning.

\section{Guideline 6: Teacher should be aware of different learning styles and personalities present in their classroom}

Among many factors that may affect second language learning, learning styles and personalities are two variables that have a great deal of influence on this process. When it comes to critical thinking and discussing controversial issues, the two most disadvantaged groups in the classroom are students with weaker language proficiencies and reserved learners who are less willing to speak up their opinions than their classmates. One solution is for teachers to organize group work and pair work as shy learners and weaker students may feel safer when working with more robust and more expressive partners. Another way is to ask the students to do writing and discussion, in which they will write down all the ideas first and discuss them as a group later. Reserved learners can be in the role of secretaries for the group, and they have to listen to opinions around their classmates and write down all the ideas.

\section{Conclusion}

In this study, we aimed to examine critical thinking in ESL curriculum in Vietnam via a questionnaire. After surveying perspectives and responses to the questionnaire from 12 lecturers and 37 students, we are now aware that Vietnamese instructors and learners hold a very hospitable view toward the incorporation of critical thinking in English language learning and teaching: our instructors acknowledged the importance of critical thinking in language learning and our learners showed a desire for becoming better critical thinkers. As we enter this digital age of information and technology, critical thinking helps both learners and teachers explore new and dangerous territories without getting contaminated by misleading information or false accounts (Purgason, 2016). For what we observe in our participants' responses, critical thinking develops learners' meta-cognitive abilities and sharpens their language skills. However, several Vietnamese instructors do not systematically introduce critical thinking due to their lack of experience, time, and resources. By providing six concrete guidelines in the previous section, we hope to contribute to the resources available to English instructors in Vietnam for practical methods for training ESL learners also to be critical thinkers. Continued research in the implementation and assessment of TESOL classrooms' critical thinking as every study has a particular context and the limitations specific to that context. In qualitative research, triangulation of sources, information, and data is one of the most important pillars to ensure the highest degree of research reliability (Patton, 1999). In this study, due to the pressure of time and the Covid-19 pandemic, we did not have the opportunity to conduct follow-up interviews with students and lecturers. Consequently, data gathered from responses to the questionnaire were the only forms of information we obtained. Second, we could have pushed the study forward a bit by surveying instructors' and learners' perspectives towards introducing critical thinking into second language assessment, which has been an unexplored area in the literature of second language pedagogy so far. There is no denying that there is a strong connection between learning, teaching, and assessment. If the teaching and learning of critical thinking are highly valued, we should soon think about assessing this ability to think in language tests, particularly in reading and writing tests. 
We are encouraged by the increasing popularity of critical thinking in TESOL and the instructors and students' openness who welcome the incorporation of critical thinking skills into TESOL contexts. This study's results highlight both the opportunities and the challenges that this undertaking will involve. However, we believe with appropriate methods and thoughtful perspectives, we can make sure our learners will be well equipped with these crucial higher-order thinking skills so that they can use their language to become more discerning thinkers, empathetic listeners, and creative problem solvers. Teaching our learners critical thinking skills and language skills is preparing them to become more ethical, confident, and capable citizens in this $21^{\text {st }}$ century digital world.

About authors

Aliel Cunningham, $\mathrm{PhD}$, is a TESOL professor at LCC International University and a TESOL Curriculum Developer for iSC (International Schools Consortium). Her current research interests include teacher professional development, curriculum development, second language prosody, and cross-cultural partnerships in TESOL contexts.

Luan Tuyen Chau is an MA TESOL student at LCC International University and a PhD researcher in Cognitive Linguistics at the University of Antwerp. His current research interests include literacy development, first and second language acquisition, developmental deficits such as dyslexia, second language pedagogy, educational psychology, and cognitive writing.

\section{References}

[1] Aldwari, M., \& Alwahedi, A. (2018). Detecting fake news in social media networks. ScienceDirect, 141, $215-222$.

[2] Atkinson, D. (1997). A critical approach to critical thinking in TESOL. TESOL Quarterly, 31(1), 71-94.

[3] Atkinson, D., \& Ramanathan, V. (1995). Cultures of writing: An ethnographic comparison of L1 and L2 university writing/language programs. TESOL Quarterly, 29, 539-568.

[4] Brualdi Timmins, A. C. (1998). Classroom Questions. Practical Assessment, Research, and Evaluation, 6(6).

[5] Chien, C. W. (2020). A case study of the use of the six thinking hats to enhance the reflective practice of student teachers in Taiwan. Education, 3-13.

[6] Chone, L. S., \& Heng, L. T. (2010). Engaging electrical engineering students in oral discussions through six thinking hats in problem based learning. 2nd International Congress on Engineering Education, (pp. 240-244). Kuala Lumpur.

[7] Hani, U., Petrus, I., \& Sitinjak, D. M. (2017). The Effct of Six Thinking Hats and Critical Thinking on Speaking Achievement. Advances in Social Science, Education and Humanities Research, 82.

[8] Hinkel, E. (2006). Current perspectives in teaching the four skills. TESOL Quarterly, 40(1), 109-131.

[9] Karadağ, M. (2009). Using the 'six thinking hats' model of learning in a surgical nursing class: sharing the experience and student opinions. Australian Journal of Advanced Nursing, 26(3).

[10] Kumaravadivelu, B. (2003). Problematizing cultural stereotypes in TESOL. TESOL Quarterly, 37(4), 709-719.

[11] Kumaravadivelu, B. (2006). TESOL methods: Challenging trends. TESOL Quarterly, 40(1), 59-81.

[12] Littlewood, W. (2000). Do Asian students really want to listen and obey? ELT Journal, 54, 31-36.

[13] Oda, M. (2008). Thinking critically about critical thinking in TESOL: East vs. West. The Journal of Asia TEFL, 5(1), 145-173.

[14] Patton, Q. M. (2000). Enhancing the quality and credibility of qualitative analysis. Health Sciences Research, 34, 1189-1208.

[15] Purgason, B. K. (2016). Good teaching: Critical thinking. In B. K. Purgason, Professional guidelines for Christian English teachers: how to be a teacher with convictions while respecting those of your students. William Carey Library.

[16] Ramanathan, V., \& Kaplan, R. B. (1996). Audience and voice in current L1 composition texts: Some implications for ESL student writers. Journal of Second Language Writing, 5, 21-34.

[17] Stapleton, P. (2002). Critical thinking in Japanese L2 writing: Rethinking tired construct. ELT Journal, 56(3), $250-257$.

[18] Swamy, C. B., Haque, I. M., Koppada, V., \& Kumar, S. N. (2019). The effect of conducting De Bono's six thinking hats activity on developing paragraph writing skills of university students in the kingdom of Saudi Arabia. International Journal of English Linguistics, 9(6). 